Research Paper

\title{
Plasma Levels of Endothelial Cell-Specific Molecule-1 as a Potential Biomarker of Oral Cancer Progression
}

\author{
Wei-En Yang, 2, Ming-Ju Hsieh², 3, 4, Chiao-Wen Lin', 6, Chun-Ying Kuo ${ }^{7}$, Shun-Fa Yang1, 2, Chun-Yi \\ Chuang $8,9 \bowtie$, Mu-Kuan Chen $2,7 \bowtie$ \\ 1. Department of Medical Research, Chung Shan Medical University Hospital, Taichung, Taiwan; \\ 2. Institute of Medicine, Chung Shan Medical University, Taichung, Taiwan; \\ 3. Cancer Research Center, Changhua Christian Hospital, Changhua, Taiwan; \\ 4. Graduate Institute of Biomedical Sciences, China Medical University, Taichung, Taiwan \\ 5. Institute of Oral Sciences, Chung Shan Medical University, Taichung, Taiwan \\ 6. Department of Dentistry, Chung Shan Medical University Hospital, Taichung, Taiwan; \\ 7. Department of Otorhinolaryngology-Head and Neck Surgery, Changhua Christian Hospital, Changhua, Taiwan; \\ 8. School of Medicine, Chung Shan Medical University, Taichung, Taiwan; \\ 9. Department of Otolaryngology, Chung Shan Medical University Hospital, Taichung, Taiwan.
}

$\square$ Corresponding authors: Mu-Kuan Chen, M.D., PhD., Department of Otorhinolaryngology-Head and Neck Surgery, Changhua Christian Hospital, Changhua, Taiwan; E-mail: 53780@cch.org.tw Or Chun-Yi Chuang, M.D., PhD., School of Medicine, Chung Shan Medical University, Taichung, Taiwan. Telephone: +886-4-24739595 ext. 34255; E-mail: cyi4602@gmail.com

(c) Ivyspring International Publisher. This is an open access article distributed under the terms of the Creative Commons Attribution (CC BY-NC) license (https://creativecommons.org/licenses/by-nc/4.0/). See http://ivyspring.com/terms for full terms and conditions.

Received: 2017.04.05; Accepted: 2017.07.05; Published: 2017.09.04

\begin{abstract}
In Taiwan, oral cancer is the fourth most common cancer and the most common malignancy with a poor prognosis. Endothelial cell-specific molecule-1 (ESM-1) is secreted by vascular endothelial cells in the liver, lungs, kidneys, and gastrointestinal tract. ESM-1 expression is associated with tumor prognosis, metastasis, and angiogenesis in many cancers. However, few studies have examined the association of plasma ESM-1 levels with oral squamous cell carcinoma (OSCC) progression. We measured the plasma ESM-1 levels of 438 male OSCC patients through a commercial enzyme-linked immunosorbent assay. The Cancer Genome Atlas (TCGA) dataset was also used to analyze the ESM-1 levels in 328 OSCC patients and 33 normal tissues. Our results revealed that the plasma levels of ESM-1 in OSCC patients were significantly associated with the tumor $(T)$ status but not with the lymph node status, metastasis, and cell differentiation. TCGA bioinformatics database analysis revealed that ESM-1 expression was significantly higher in OSCC patients than in normal individuals $(p<0.05)$. In addition, the examination revealed similar results for the ESM-1 expression levels and pathological stage in OSCC. In conclusion, plasma ESM- 1 is a novel biomarker for predicting the T status in OSCC patients.
\end{abstract}

Key words: ESM-1, oral squamous cell carcinoma, biomarker.

\section{Introduction}

Oral cancer, which involves malignant tumors that affect any region of the oral cavity, lip, salivary glands, and pharyngeal regions, is a major problem concerning human health worldwide. Oral squamous cell carcinoma (OSCC) is the most frequently (approximately 90\%) occurring malignant oral cancer, and the incidence and prevalence have increased in recent years, especially in Asian countries [1-3]. The major risk factors for oral cancer are smoking and alcohol, which have been noted in $90 \%$ of oral cancer cases [4]. Surgery is the preferred treatment approach for OSCC. The recurrence of OSCC is due to local metastasis and invasion, leading to a poor prognosis $[5,6]$. Therefore, more accurate and acceptable biomarkers must be developed for early cancer detection and to predict OSCC progression.

Endothelial cell-specific molecule-1 (ESM-1) or endocan is a $50-\mathrm{kDa}$ secretory proteoglycan composed of a 165 -amino acid mature protein core $(20 \mathrm{kDa})$ and approximately $30 \mathrm{kDa}$ of a unique dermatan sulfate chain linked to serine residues [7-9]. It is predominantly secreted by vascular endothelial cells from the liver, lungs, gastrointestinal tract, and kidneys [10, 11]. ESM-1 production is highly 
regulated by the environment. Angiogenic factors and inflammatory cytokines, such as interleukin (IL)-1 $\beta$ and tumor necrosis factor- $\alpha$ (TNF- $\alpha$ ), induce ESM-1 expression and are strongly downregulated by IL-4 and interferon- $\gamma[7,8,10]$. ESM-1 is expressed not only in normal tissues but also in various types of tumors, with differential expression levels in glioblastoma [12], non-small cell lung cancer [13], gastric cancer [14], colorectal cancer [14], renal cell cancer [15, 16], bladder cancer [17], ovarian cancer [18], hepatocellular carcinoma [19], and acute myeloid leukemia [20]. ESM-1 plays an influential role in angiogenesis and tumor growth. In tumor tissues, angiogenesis is crucial for progression and is an indicator of poor prognosis. ESM-1 levels are associated with increased proangiogenesis growth factors, such as fibroblast growth factor-2 (FGF-2), vascular endothelial growth factor (VEGF), and hepatocyte growth factor/scatter factor, and are regulated by VEGF [8, 21]. ESM-1 is also overexpressed at the mRNA and/or protein levels in cancer tissues, and it has been related to tumor progression and poorer survival [22, 23]. Moreover, a meta-analysis study which including 15 eligible studies of 1,464 patients also mentioned that high ESM-1 expression predicts poor overall survival in gastrointestinal and hepatocellular carcinoma [24].

Previously, ESM-1 has been observed not only in the serum of septic patients [25] but also as a potential serum biomarker in gastric cancer [26], bladder cancer [27], colorectal cancer [28] and hepatocellular carcinoma [29] patients. Furthermore, higher levels of serum ESM-1 are correlated with a poor prognosis [30]. However, whether serum ESM-1 levels are elevated in OSCC patients remains unclear, and the association between the serum levels of ESM-1 and prognosis of OSCC patients has not been elucidated. The present study examined whether serum ESM-1 can be used as a biomarker for the early diagnosis of OSCC.

\section{Materials and Methods}

\section{Patient Specimens}

In total, 438 OSCC male patients (mean age, 55.23 years) from 2008 to 2012 were recruited from Chung Shan Medical University Hospital in Taichung and Changhua Christian Hospital in Changhua, Taiwan. Data of the tumor stage, tumor, node, and metastasis (TNM) status and cell differentiation were obtained from the medical records of the OSCC patients. The OSCC patients were diagnosed according to the TNM classification, which is described in the American Joint Committee on Cancer (AJCC) Staging Manual, seventh edition.
Whole peripheral blood samples were collected from OSCC patients and placed in EDTA tubes. After the centrifugation of the blood samples at $3000 \mathrm{rpm}$ for $10 \mathrm{~min}$, the supernatants were placed at $-80^{\circ} \mathrm{C}$. This study was approved by the Institutional Review Board of Chung Shan Medical University Hospital (CSMUH No: CS13214-1), and informed written consent for participation was obtained from all participants. Table 1 shows the clinical characteristics of the patients.

Table 1. Demographic characteristics and clinical features of OSCC patients.

\begin{tabular}{|c|c|}
\hline Variables & $\operatorname{OSCC}(n=438)$ \\
\hline Age (years) & $55.23 \pm 10.82$ \\
\hline \multicolumn{2}{|l|}{ Smoking status } \\
\hline No & 46 (10.5\%) \\
\hline Yes & $392(89.5 \%)$ \\
\hline \multicolumn{2}{|l|}{ Drinking status } \\
\hline No & $205(46.8 \%)$ \\
\hline Yes & $233(53.2 \%)$ \\
\hline \multicolumn{2}{|l|}{ Betel nuts chewing } \\
\hline No & $86(19.6 \%)$ \\
\hline Yes & $352(80.4 \%)$ \\
\hline \multicolumn{2}{|l|}{ Cancer location } \\
\hline Buccal mucosa & $157(35.8 \%)$ \\
\hline Tongue & $130(29.7 \%)$ \\
\hline Gingiva & $68(15.5 \%)$ \\
\hline Others & $83(18.9 \%)$ \\
\hline \multicolumn{2}{|l|}{ Stage } \\
\hline I & $118(27.0 \%)$ \\
\hline II & $79(18.0 \%)$ \\
\hline III & $43(9.8 \%)$ \\
\hline IV & $198(45.2 \%)$ \\
\hline \multicolumn{2}{|l|}{ Tumor T status } \\
\hline $\mathrm{T} 1$ & $141(32.2 \%)$ \\
\hline $\mathrm{T} 2$ & $120(27.4 \%)$ \\
\hline T3 & $37(8.4 \%)$ \\
\hline $\mathrm{T} 4$ & $140(32.0 \%)$ \\
\hline \multicolumn{2}{|l|}{ Lymph node status } \\
\hline No & $287(65.5 \%)$ \\
\hline N1 & $48(11.0 \%)$ \\
\hline N2 & $99(22.6 \%)$ \\
\hline N3 & $4(0.9 \%)$ \\
\hline \multicolumn{2}{|l|}{ Metastasis } \\
\hline M0 & $436(99.5 \%)$ \\
\hline M1 & $2(0.5 \%)$ \\
\hline \multicolumn{2}{|l|}{ Cell differentiation } \\
\hline Well differentiated & $59(13.5 \%)$ \\
\hline $\begin{array}{l}\text { Moderately or poorly } \\
\text { differentiated }\end{array}$ & $379(86.5 \%)$ \\
\hline
\end{tabular}

\section{Quantitative Analysis of Plasma ESM-1 Levels}

The ESM-1 levels in the plasma samples of OSCC were analyzed using an ESM-1 Human ELISA Kit (LIK-1205, Lunginnov, Lille, France). The prepared standards and samples were added to an ELISA plate, according to the manufacturer instructions. After reading the absorbance of each well at $450 \mathrm{~nm}$ in a microtest plate spectrophotometer (STNERGY/H4, BioTek Instruments, Inc., Winoosi, VT, USA), the 
ESM-1 levels were quantified using a calibration curve, with the provided human ESM-1 as a standard.

\section{Expression Analysis of The Cancer Genome Atlas OSCC data}

The Cancer Genome Atlas (TCGA; URL: https://tcga-data.nci.nih.gov/tcga/) was used to obtain the ESM-1 normalized expression data and associated clinical data, which corresponds to the head and neck squamous cell carcinoma dataset $(\mathrm{n}=$ 528). After filtering the samples, we included only one of six oral cancer anatomic subtypes (alveolar ridge, base of tongue, buccal mucosa, floor of mouth, oral cavity, and oral tongue; filtered oral cancer dataset size: $\mathrm{n}=328$ ). Box plots for ESM-1 expression values were generated with respect to the tumor grade/stage and TNM status.

\section{Statistical Analysis}

The standard deviation of the mean was used to express the values. The statistical significance of the means for ESM-1 levels was determined using the Mann-Whitney Rank sum test between groups. In addition, alcohol consumption status, smoking status, and betel nuts chewing status were analyzed using the Chi-squared test. Student t-test was used to calculate the significances of the differences. Analyses were performed using SPSS 16.0 statistical software (SPSS Inc., Chicago, IL, USA). Statistical significance was set at $\mathrm{p}<0.05$.

\section{Results}

\section{Demographic Data}

In this study, only male OSCC patients $(n=438)$ were included. The demographic data presents the tumor stage, TNM status, and tumor differentiation status of these patients (Table 1). Among these patients, $89.5 \%$ smoked, $53.2 \%$ consumed alcohol, and $80.4 \%$ chewed betel nut. The tumors were located in the buccal mucosa $(n=157)$, tongue $(n=130)$, gingiva $(\mathrm{n}=68)$, and other parts $(\mathrm{n}=83)$.

\section{Correlation of Plasma ESM-1 Levels and Clinicopathological Characteristics of OSCC Patients}

The mean plasma ESM-1 levels were significantly higher in stage II patients $(2.58 \pm 1.39$ $\mathrm{ng} / \mathrm{mL})$ than in stage I $(2.1 \pm 1.32 \mathrm{ng} / \mathrm{mL})$ patients $(\mathrm{p}$ $=0.016$; Figure 1A). In addition, the mean plasma ESM-1 levels were significantly higher in patients with T2 status $(2.47 \pm 1.31 \mathrm{ng} / \mathrm{mL})$ than in patients with T1 status $(2.09 \pm 1.32 \mathrm{ng} / \mathrm{mL})(\mathrm{p}=0.021$; Figure 1B). No significant differences were noted between the $\mathrm{N}$ statuses (Figure 1C). The correlation of plasma ESM-1 levels with the clinicopathological characteristics is presented in Table 2. High plasma ESM-1 levels were significantly associated with the T status. Compared with patients with low plasma ESM-1 levels, a higher proportion of patients with high plasma ESM-1 levels had T1-T3 status (77.3\% vs. $62.2 \% ; p=0.001)$.

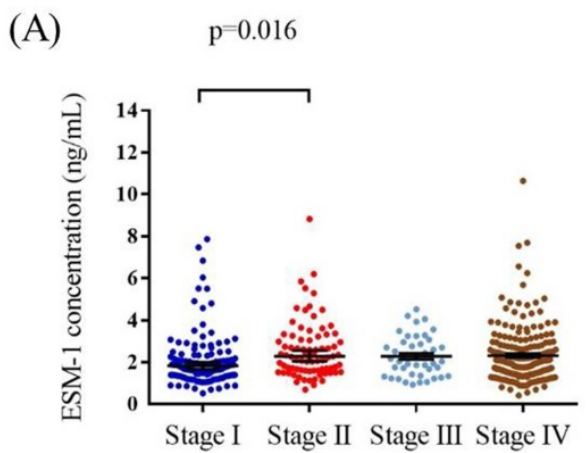

(B)

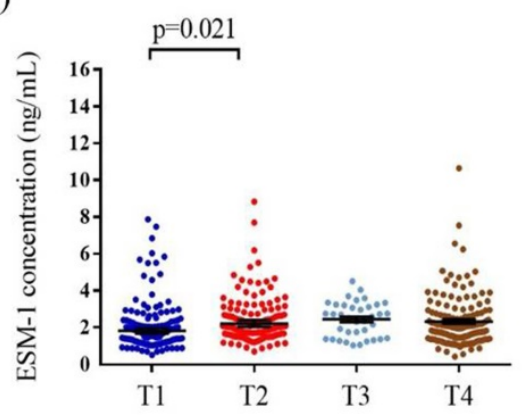

(C)

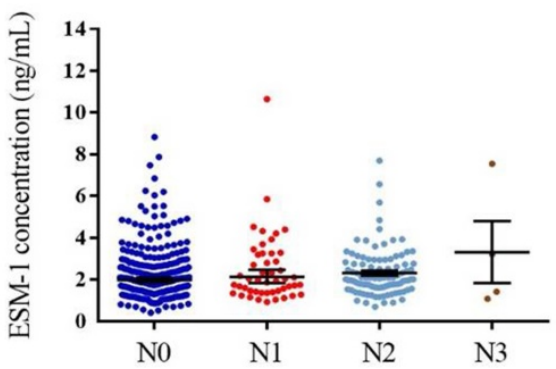

Figure 1. ELISA-determined plasma ESM-1 level of OSCC patients. ESM-1 levels were compared according to stage (A), T status (B) and N status (C). 


\section{Correlation of ESM-1 Levels and Clinicopathological Characteristics of OSCC Patients From TCGA}

TCGA OSCC database was used to verify the findings of our study. The ESM-1 mRNA levels, pathological stage, pathological $\mathrm{T}$ and $\mathrm{N}$ status of OSCC, and normal tissues were assessed. The ESM-1 expression levels in different cancer types are shown in Figure 2A. Higher ESM-1 levels were detected in OSCC tissues than in normal tissues $(p=0.03$; Figure 2B). Among the OSCC patients, the relative levels of ESM-1 mRNA were significantly higher in stage III patients than in stage I patients $(p=0.0221$; Figure 2C). The relative levels of ESM-1 mRNA were significantly higher in patients with $\mathrm{T} 3$ status than in patients with $\mathrm{T} 1$ status $(\mathrm{p}=0.0138$; Figure 2D). However, the relative levels of ESM-1 mRNA were not significantly associated with the $\mathrm{N}$ status (Figure 2E).

Table 2. Correlation between plasma levels of ESM-1 and clinicopathological parameters in 438 OSCC patients.

\begin{tabular}{|c|c|c|c|}
\hline & ESM-1 levels & & $\mathrm{p}$ value \\
\hline Variables & $\begin{array}{l}\text { Low levels } \\
(n=275)\end{array}$ & High levels $(n=163)$ & \\
\hline \multicolumn{4}{|l|}{ Age (years) } \\
\hline$<55$ & $143(52.0 \%)$ & $66(40.5 \%)$ & $0.020^{*}$ \\
\hline$\geq 55$ & $132(48.0 \%)$ & $97(59.5 \%)$ & \\
\hline \multicolumn{4}{|l|}{ Smoking status } \\
\hline No & $28(10.2 \%)$ & $18(11.0 \%)$ & 0.776 \\
\hline Yes & $247(89.8 \%)$ & $145(89.0 \%)$ & \\
\hline \multicolumn{4}{|l|}{ Drinking status } \\
\hline No & $116(42.2 \%)$ & $89(54.6 \%)$ & $0.012^{*}$ \\
\hline Yes & $159(57.8 \%)$ & $74(45.4 \%)$ & \\
\hline \multicolumn{4}{|l|}{ Betel nuts chewing } \\
\hline No & $53(19.3 \%)$ & $33(20.2 \%)$ & 0.804 \\
\hline Yes & $222(80.7 \%)$ & $130(79.8 \%)$ & \\
\hline \multicolumn{4}{|l|}{ Cancer location } \\
\hline Buccal mucosa & $109(39.6 \%)$ & $48(27.4 \%)$ & 0.196 \\
\hline Tongue & $76(27.6 \%)$ & $54(33.2 \%)$ & \\
\hline Gingiva & $40(14.5 \%)$ & $28(17.2 \%)$ & \\
\hline Others & $50(18.3 \%)$ & $33(20.2 \%)$ & \\
\hline \multicolumn{4}{|l|}{ Stage } \\
\hline $\mathrm{I}+\mathrm{II}$ & $127(46.2 \%)$ & $71(43.6 \%)$ & 0.594 \\
\hline III+IV & $148(53.8 \%)$ & $92(56.4 \%)$ & \\
\hline \multicolumn{4}{|l|}{ Tumor T status } \\
\hline $\mathrm{T} 1$ & $104(37.8 \%)$ & $37(22.7 \%)$ & $0.001^{*}$ \\
\hline $\mathrm{T} 2+\mathrm{T} 3+\mathrm{T} 4$ & $171(62.2 \%)$ & $126(77.3 \%)$ & \\
\hline \multicolumn{4}{|l|}{ Lymph node status } \\
\hline N0 & $184(66.9 \%)$ & $103(63.2 \%)$ & 0.429 \\
\hline $\mathrm{N} 1+\mathrm{N} 2+\mathrm{N} 3$ & $91(33.1 \%)$ & $60(36.8 \%)$ & \\
\hline \multicolumn{4}{|l|}{ Metastasis } \\
\hline M0 & $275(100.0 \%)$ & $161(98.8 \%)$ & 0.066 \\
\hline M1 & $0(0 \%)$ & $2(1.2 \%)$ & \\
\hline \multicolumn{4}{|l|}{ Cell differentiation } \\
\hline Well differentiated & $37(13.5 \%)$ & $22(13.5 \%)$ & 0.990 \\
\hline $\begin{array}{l}\text { Moderately or } \\
\text { poorly } \\
\text { differentiated }\end{array}$ & $238(86.5 \%)$ & $141(86.5 \%)$ & \\
\hline
\end{tabular}

\section{Discussion}

ESM-1 is a soluble proteoglycan and a freely circulating molecule in the blood; hence, it has high potential as a biomarker. This is the first study to investigate the potential roles of ESM-1 in the peripheral blood of OSCC patients and the association between the plasma ESM-1 levels and clinicopathological characteristics. In this study, the plasma ESM-1 levels of OSCC patients were significantly associated with the tumor stage and $\mathrm{T}$ status. Similar results were also obtained in TCGA bioinformatics database analysis.

Tumor progression is a complex process, and the microenvironment not only plays a crucial role in cancer progression but also has profound effects on metastasis and angiogenesis [31-34]. ESM-1 expression is regulated by various cytokines and cell factors, such as IL-1 and TNF- $\alpha$, which may promptly induce increased serum ESM-1 expression to regulate tumor-associated inflammation [25]. Increased ESM-1 expression by endothelial cells is associated with certain angiogenic factors, such as FGF-2 and VEGF-A [35]. In human renal cancer, VEGF-A regulates ESM-1 expression through the PI3K/Akt signaling pathway and the protein kinase $C$ activator [15]; VEGF-C and nuclear factor-kB (NF-kB) upregulate ESM-1. In ESM-1 knockout mice, vascular outgrowth was delayed, filopodia extension was reduced, phosphorylated Erk1/2 (extracellular signal-regulated kinases $1 / 2$ ) expression in sprouting vessels was decreased, and VEGF-A-dependent processes were effected [35]. Thus, ESM-1 plays a role in angiogenesis and inflammation. Numerous studies have demonstrated that ESM-1 can be used as a potential biomarker for detection in gastric cancer [36], bladder cancer [37], colorectal cancer [28], hepatocellular carcinoma [38], pituitary adenoma [39], ovarian cancer [40], breast cancer [41], and acute leukemia [20], but ESM-1 has not been investigated in OSCC.

In various cancers, higher than normal ESM-1 expression levels have been detected. In addition, tumor size has been positively correlated with circulating ESM-1 expression levels. In colorectal cancer, knockdown ESM-1 expression may affect cell cycle arrest, decrease cyclin D1, and regulate metastatic process through the decline of NF- $\mathrm{kB}$, phosphor-Akt, and GSK3a/3 $\beta$ expression [42]. In SK-Hep1 cells, ESM-1 siRNA expression indicates that ESM-1 may increase the survival rate through the

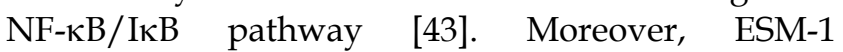
expression was associated with higher serum alpha fetoprotein levels and larger tumor in early hepatocellular carcinoma [44]. The metastatic process 
is also inhibited through the regulation of matrix metalloproteinase (MMP)- and epithelial-to-mesenchymal transition-related genes in cells with lower ESM-1 expression [42]. In murine OSCC, ESM-1 mediates nerve growth factor receptor (NGFR)-induced metastasis and invasion. Cells with ESM-1 overexpression may exhibit enhanced cell invasion and migration in vitro. In severe combined immunodeficient mice with NGFR-induced tumors, ESM-1 knockdown cells may reduce tumor formation and metastasis [45]. However, our study did not examine the regulation of plasma ESM-1 levels. In the future, we will examine the possible mechanisms of ESM-1 expression in OSCC.

(A)

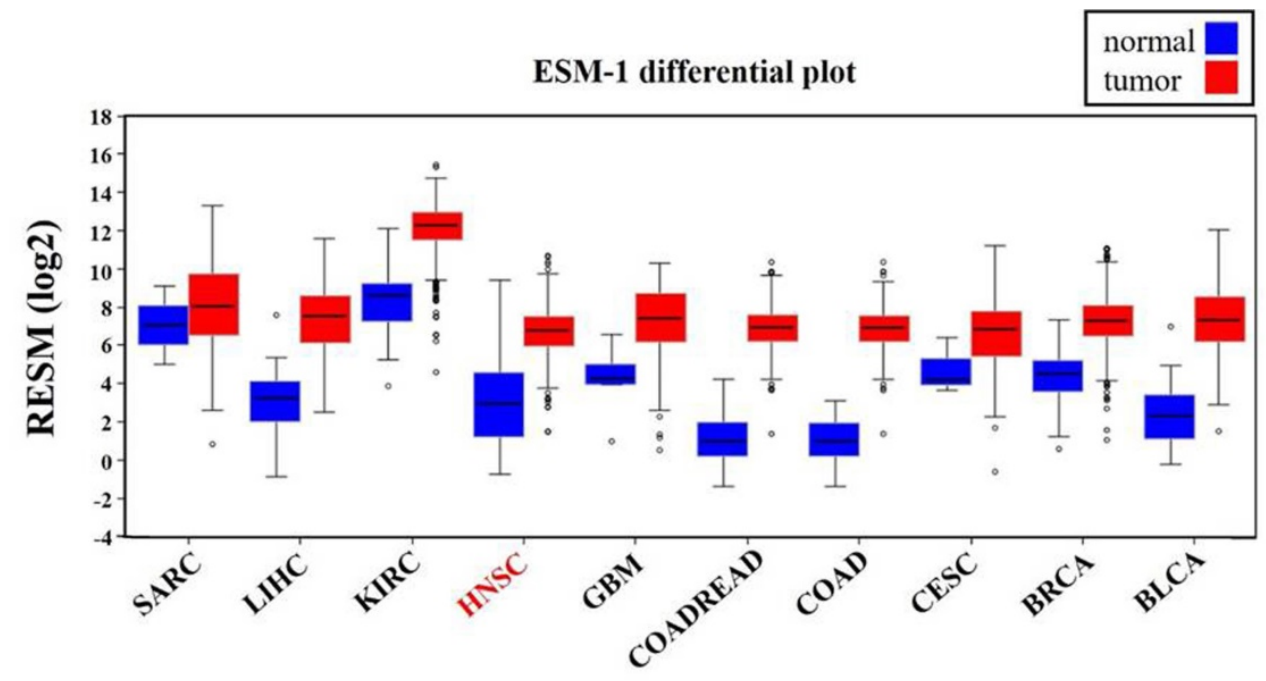

(B)

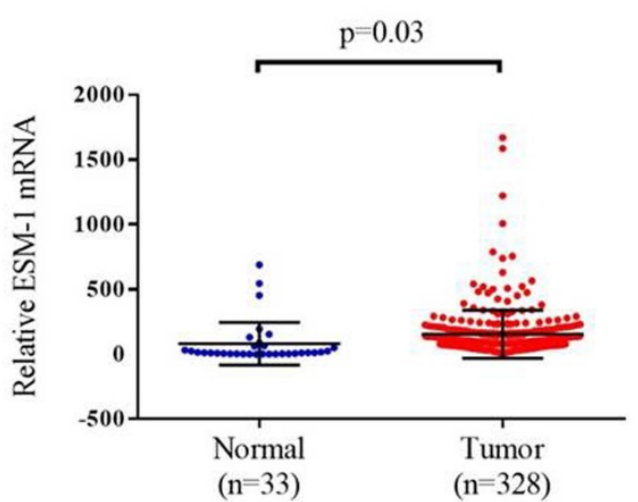

(C)

(D)

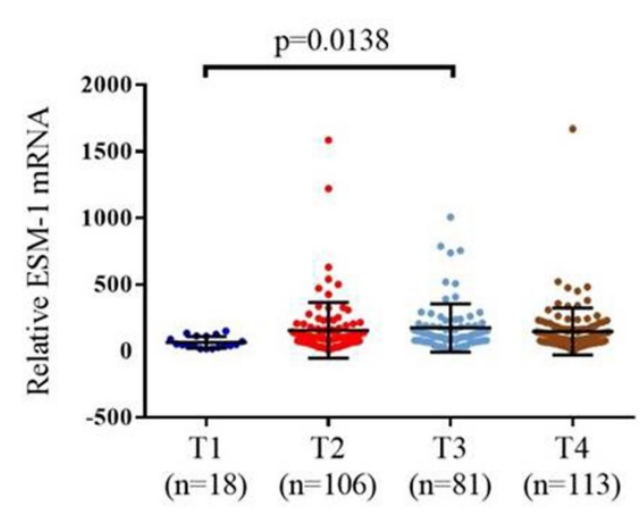

(E)
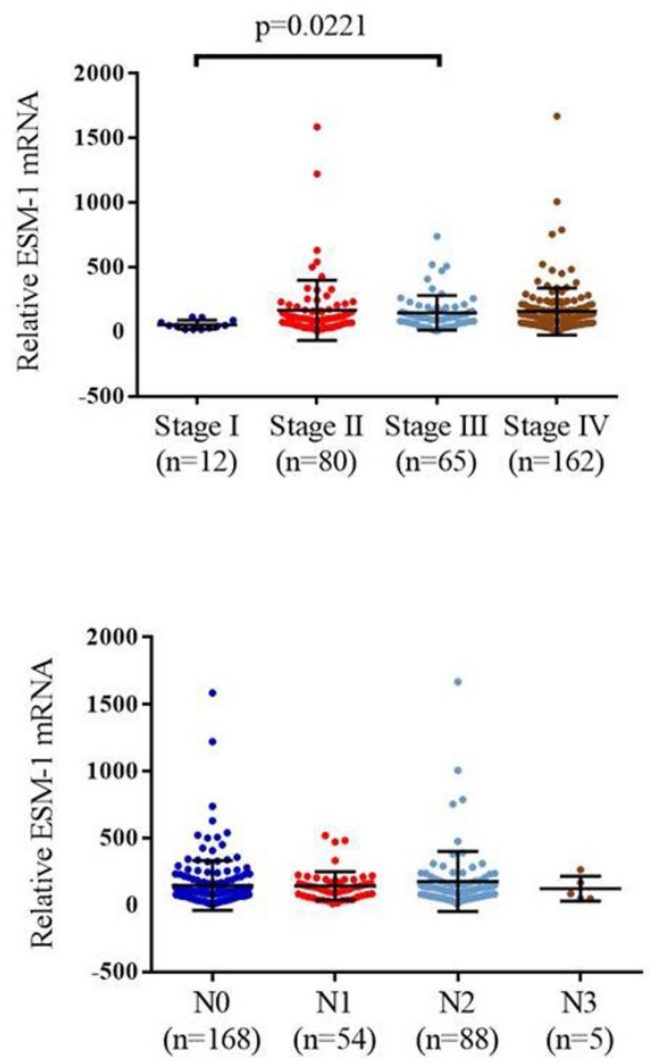

Figure 2. ESM-1 mRNA level of OSCC patients from TCGA database. (A) The different of ESM-1 mRNA level from The Broad Institute TCGA GDAC Firehose in different type of cancer. (B) ESM-1 levels were compared according to normal people and OSCC patients. (C) ESM-1 levels were compared according to stage. (D) ESM-1 levels were compared according to tumor T status. (E) ESM-1 levels were compared according to N status. SARC: sarcoma. LIHC: liver hepatocellular carcinoma. KIRC: kidney renal clear cell carcinoma. HNSC: head and neck squamous cell carcinoma. GBM: Glioblastoma multiforme. COADREAD: colorectal adenocarcinoma. COAD: colon adenocarcinoma. CESC: cervical and endocervical cancers. BRCA: breast invasive carcinoma. BLCA: bladder urothelial carcinoma. 
Most studies have indicated that ESM-1 is overexpressed in various cancer types and is associated with tumor progression and poor prognosis. However, contrary results have been reported in prostate cancer cells. Knockdown ESM-1 enhanced cell viability, cell migration, and cell invasion in vitro and increased the tumorigenesis and metastasis of prostate xenograft tumors in vivo through the regulation of TIMP-1/MMP-9 expression. ESM-1 plays a role in tumor suppression in prostate cancer cells [46].

In conclusion, our study revealed that plasma ESM-1 levels are useful for the detection of disease progression in OSCC patients. This is the first study to analyze plasma ESM-1 levels in patients with OSCC. We demonstrated that plasma ESM-1 levels were significantly associated with the $\mathrm{T}$ status in OSCC patients. As a secreted protein, ESM-1 may act as a potential marker of OSCC during tumor progression and can accordingly be used for disease diagnosis; furthermore, it plays a critical role in carcinogenesis.

\section{Acknowledgments}

This study was financially supported by grants from Ministry of Science and Technology, Taiwan (MOST-104-2314-B-371-008-MY2), Chung Shan Medical University and Changhua Christian Hospital (CSMU-CCH-105-04). This study was supported by the grant from Chang Shan Medical University Hospital (CSH-2017-C-016).

\section{Competing Interests}

The authors have declared that no competing interest exists.

\section{References}

[1] Choi S and Myers JN. Molecular pathogenesis of oral squamous cell carcinoma: implications for therapy. J Dent Res 2008; 87: 14-32.

[2] Bagan JV and Scully C. Recent advances in Oral Oncology 2007: epidemiology, aetiopathogenesis, diagnosis and prognostication. Oral Oncol 2008; 44: 103-108.

[3] Su SC, Lin CW, Liu YF, Fan WL, Chen MK, Yu CP, Yang WE, Su CW, Chuang $\mathrm{CY}, \mathrm{Li} \mathrm{WH}$, Chung WH and Yang SF. Exome Sequencing of Oral Squamous Cell Carcinoma Reveals Molecular Subgroups and Novel Therapeutic Opportunities. Theranostics 2017; 7: 1088-1099.

[4] Dissanayaka WL, Pitiyage G, Kumarasiri PV, Liyanage RL, Dias KD and Tilakaratne WM. Clinical and histopathologic parameters in survival of oral squamous cell carcinoma. Oral Surg Oral Med Oral Pathol Oral Radiol 2012; 113: 518-525.

[5] Rivera C. Essentials of oral cancer. Int J Clin Exp Pathol 2015; 8: 11884-11894.

[6] Su SC, Hsieh MJ, Yang WE, Chung WH, Reiter RJ and Yang SF. Cancer metastasis: Mechanisms of inhibition by melatonin. J Pineal Res 2017; 62: e12370.

[7] Lassalle P, Molet S, Janin A, Van der Heyden J, Tavernier J, Fiers W, Devos R and Tonnel A-B. ESM-1 Is a Novel Human Endothelial Cell-specific Molecule Expressed in Lung and Regulated by Cytokines. J Biol Chem 1996; 271: 20458-20464.

[8] Sarrazin S, Adam E, Lyon M, Depontieu F, Motte V, Landolfi C, Lortat-Jacob $\mathrm{H}$, Bechard D, Lassalle P and Delehedde M. Endocan or endothelial cell specific molecule-1 (ESM-1): a potential novel endothelial cell marker and a new target for cancer therapy. Biochim Biophys Acta 2006; 1765: 25-37.

[9] Béchard D, Gentina T, Delehedde M, Scherpereel A, Lyon M, Aumercier M, Vazeux R, Richet C, Degand P, Jude B, Janin A, Fernig DG, Tonnel A-B and Lassalle P. Endocan is a novel chondroitin sulfate / dermatan sulfate proteoglycan which promotes hepatocyte growth factor/scatter factor mitogenic activity. J Biol Chem 2001; 276: 48341-48349.

[10] Bechard D, Meignin V, Scherpereel A, Oudin S, Kervoaze G, Bertheau P, Janin $\mathrm{A}$, Tonnel $\mathrm{AB}$ and Lassalle P. Characterization of the Secreted Form of Endothelial-Cell-Specific Molecule 1 by Specific Monoclonal Antibodies. J Vasc Res 2000; 37: 417-425.

[11] Zhang SM, Zuo L, Zhou Q, Gui SY, Shi R, Wu Q, Wei W and Wang Y. Expression and distribution of endocan in human tissues. Biotech Histochem 2012; 87: 172-178.

[12] Maurage CA, Adam E, Mineo JF, Sarrazin S, Debunne M, Siminski RM, Baroncini M, Lassalle P, Blond S and Delehedde M. Endocan expression and localization in human glioblastomas. J Neuropathol Exp Neurol 2009; 68: 633-641.

[13] Grigoriu BD, Depontieu F, Scherpereel A, Gourcerol D, Devos P, Ouatas T, Lafitte JJ, Copin MC, Tonnel AB and Lassalle P. Endocan expression and relationship with survival in human non-small cell lung cancer. Clin Cancer Res 2006; 12: 4575-4582.

[14] Liu N, Zhang LH, Du H, Hu Y, Zhang GG, Wang XH, Li JY and Ji JF. Overexpression of endothelial cell specific molecule-1 (ESM-1) in gastric cancer. Ann Surg Oncol 2010; 17: 2628-2639.

[15] Rennel E, Mellberg S, Dimberg A, Petersson L, Botling J, Ameur A, Westholm JO, Komorowski J, Lassalle P, Cross MJ and Gerwins P. Endocan is a VEGF-A and PI3K regulated gene with increased expression in human renal cancer. Exp Cell Res 2007; 313: 1285-1294.

[16] Leroy X, Aubert S, Zini L, Franquet H, Kervoaze G, Villers A, Delehedde M, Copin M-C and Lassalle P. Vascular endocan (ESM-1) is markedly overexpressed in clear cell renal cell carcinoma. Histopathology 2010; 56: 180-187.

[17] Roudnicky F, Poyet C, Wild P, Krampitz S, Negrini F, Huggenberger R, Rogler A, Stöhr R, Hartmann A, Provenzano M, Otto VI and Detmar M. Endocan Is Upregulated on Tumor Vessels in Invasive Bladder Cancer Where It Mediates VEGF-A-Induced Angiogenesis. Cancer Res 2013; 73: 1097-1106.

[18] El Behery MM, Seksaka MA, Ibrahiem MA, Saleh HS and El Alfy Y. Clinicopathological correlation of endocan expression and survival in epithelial ovarian cancer. Arch Gynecol Obstet 2013; 288: 1371-1376.

[19] Huang G-W, Tao Y-M and Ding X. Endocan Expression Correlated with Poor Survival in Human Hepatocellular Carcinoma. Dig Dis Sci 2009; 54: 389-394.

[20] Xu Z, Zhang S, Zhou Q, Wang Y and Xia R. Endocan, a potential prognostic and diagnostic biomarker of acute leukemia. Mol Cell Biochem 2014; 395: 117-123.

[21] Scherpereel A, Gentina T, Grigoriu B, Senechal S, Janin A, Tsicopoulos A, Plenat F, Bechard D, Tonnel AB and Lassalle P. Overexpression of endocan induces tumor formation. Cancer Res 2003; 63: 6084-6089.

[22] Grigoriu BD, Depontieu F, Scherpereel A, Gourcerol D, Devos P, Ouatas T, Lafitte J-J, Copin M-C, Tonnel A-B, Lassalle P and Group TTO. Endocan Expression and Relationship with Survival in Human Non-Small Cell Lung Cancer. Clin Cancer Res 2006; 12: 4575-4582.

[23] El Behery MM, Seksaka MA, Ibrahiem MA, Saleh HS and El Alfy Y. Clinicopathological correlation of endocan expression and survival in epithelial ovarian cancer. Arch Gynecol Obstet 2013; 288: 1371-1376.

[24] Huang X, Chen C, Wang X, Zhang JY, Ren BH, Ma DW, Xia L, Xu XY and Xu L. Prognostic value of endocan expression in cancers: evidence from meta-analysis. Onco Targets Ther 2016; 9: 6297-6304.

[25] Scherpereel A, Depontieu F, Grigoriu B, Cavestri B, Tsicopoulos A, Gentina T, Jourdain M, Pugin J, Tonnel AB and Lassalle P. Endocan, a new endothelial marker in human sepsis. Crit Care Med 2006; 34: 532-537.

[26] Lv Z, Fan Y, Chen H and Zhao D. Endothelial cell-specific molecule-1: a potential serum marker for gastric cancer. Tumor Biol 2014; 35: 10497-10502.

[27] Laloglu E, Aksoy H, Aksoy Y, Ozkaya F and Akcay F. The determination of serum and urinary endocan concentrations in patients with bladder cancer. Ann Clin Biochem 2016;

[28] Ji NY, Kim YH, Jang YJ, Kang YH, Lee CI, Kim JW, Yeom YI, Chun HK, Choi YH, Kim JH, Kim JW, Lee HG and Song EY. Identification of endothelial cell-specific molecule-1 as a potential serum marker for colorectal cancer. Cancer Sci 2010; 101: 2248-2253.

[29] Ozaki K, Toshikuni N, George J, Minato T, Matsue Y, Arisawa T and Tsutsumi M. Serum Endocan as a Novel Prognostic Biomarker in Patients with Hepatocellular Carcinoma. J Cancer 2014; 5: 221-230.

[30] Huang GW, Tao YM and Ding X. Endocan expression correlated with poor survival in human hepatocellular carcinoma. Dig Dis Sci 2009; 54: 389-394.

[31] Su SC, Lin CW, Yang WE, Fan WL and Yang SF. The urokinase-type plasminogen activator (uPA) system as a biomarker and therapeutic target in human malignancies. Expert Opin Ther Targets 2016; 20: 551-566.

[32] Reiter RJ, Rosales-Corral SA, Tan DX, Acuna-Castroviejo D, Qin L, Yang SF and $\mathrm{Xu} \mathrm{K}$. Melatonin, a Full Service Anti-Cancer Agent: Inhibition of Initiation, Progression and Metastasis. Int J Mol Sci 2017; 18: E843.

[33] Chien MH, Lin CW, Cheng CW, Wen YC and Yang SF. Matrix metalloproteinase-2 as a target for head and neck cancer therapy. Expert Opin Ther Targets 2013; 17: 203-216.

[34] Ho HY, Lin CW, Chien MH, Reiter RJ, Su SC, Hsieh YH and Yang SF. Melatonin suppresses TPA-induced metastasis by downregulating matrix metalloproteinase-9 expression through JNK/SP-1 signaling in nasopharyngeal carcinoma. J Pineal Res 2016; 61: 479-492.

[35] Yang J, Yang Q, Yu S and Zhang X. Endocan: A new marker for cancer and a target for cancer therapy. Biomed Rep 2015; 3: 279-283. 
[36] Chang Y, Niu W, Lian PL, Wang XQ, Meng ZX, Liu $Y$ and Zhao R. Endocan-expressing microvessel density as a prognostic factor for survival in human gastric cancer. World J Gastroenterol 2016; 22: 5422-5429.

[37] Roudnicky F, Poyet C, Wild P, Krampitz S, Negrini F, Huggenberger R, Rogler A, Stohr R, Hartmann A, Provenzano M, Otto VI and Detmar M. Endocan is upregulated on tumor vessels in invasive bladder cancer where it mediates VEGF-A-induced angiogenesis. Cancer Res 2013; 73: 1097-1106.

[38] Nault JC, Guyot E, Laguillier C, Chevret S, Ganne-Carrie N, N'Kontchou G, Beaugrand M, Seror O, Trinchet JC, Coelho J, Lasalle P, Charnaux N, Delehedde M, Sutton A and Nahon P. Serum proteoglycans as prognostic biomarkers of hepatocellular carcinoma in patients with alcoholic cirrhosis. Cancer Epidemiol Biomarkers Prev 2013; 22: 1343-1352.

[39] Cornelius A, Cortet-Rudelli C, Assaker R, Kerdraon O, Gevaert MH, Prevot V, Lassalle P, Trouillas J, Delehedde $\mathrm{M}$ and Maurage CA. Endothelial expression of endocan is strongly associated with tumor progression in pituitary adenoma. Brain Pathol 2012; 22: 757-764.

[40] Laloglu E, Kumtepe Y, Aksoy H and Topdagi Yilmaz EP. Serum endocan levels in endometrial and ovarian cancers. J Clin Lab Anal 2016; doi: 10.1002/jcla.22079.

[41] Sagara A, Igarashi K, Otsuka M, Kodama A, Yamashita M, Sugiura R, Karasawa T, Arakawa K, Narita M, Kuzumaki N, Narita M and Kato Y. Endocan as a prognostic biomarker of triple-negative breast cancer. Breast Cancer Res Treat 2017; 161: 269-278.

[42] Kang YH, Ji NY, Han SR, Lee CI, Kim JW, Yeom YI, Kim YH, Chun HK, Kim JW, Chung JW, Ahn DK, Lee HG and Song EY. ESM-1 regulates cell growth and metastatic process through activation of NF-kappaB in colorectal cancer. Cell Signal 2012; 24: 1940-1949.

[43] Kang YH, Ji NY, Lee CI, Lee HG, Kim JW, Yeom YI, Kim DG, Yoon SK, Kim JW, Park PJ and Song EY. ESM-1 silencing decreased cell survival, migration, and invasion and modulated cell cycle progression in hepatocellular carcinoma. Amino Acids 2011; 40: 1003-1013.

[44] Ziol M, Sutton A, Calderaro J, Barget N, Aout M, Leroy V, Blanc JF, Sturm N, Bioulac-Sage P, Nahon P, Nault JC, Charnaux N, N'Kontchou G, Trinchet JC, Delehedde M, Seror O, Beaugrand M, Vicaut E and Ganne-Carrie N. ESM-1 expression in stromal cells is predictive of recurrence after radiofrequency ablation in early hepatocellular carcinoma. J Hepatol 2013; 59: 1264-1270.

[45] Chen C, Shin JH, Eggold JT, Chung MK, Zhang LH, Lee J and Sunwoo JB. ESM1 mediates NGFR-induced invasion and metastasis in murine oral squamous cell carcinoma. Oncotarget 2016; 7: 70738-70749.

[46] Chen CM, Lin CL, Chiou HL, Hsieh SC, Lin CL, Cheng CW, Hung CH, Tsai JP and Hsieh $\mathrm{YH}$. Loss of endothelial cell-specific molecule 1 promotes the tumorigenicity and metastasis of prostate cancer cells through regulation of the TIMP-1/MMP-9 expression. Oncotarget 2017; 8: 13886-13897. 